\section{Antimicrobial Effects of Silver Nanoparticles Stabilized in Solution by Sodium Alginate}

\section{Abstract}

Background/purpose: To investigate the effect of nanosilver particles in solution stabilized in a matrix of sodium alginate on the growth and development of pathogenic bacteria such as Staphylococcus aureus, Enterococcus faecalis, Escherichia coli, Proteus vulgaris, Enterobacter cloacae, the antibiotic-resistant strain of Pseudomonas aeruginosa, the yeast-like fungus Candida albicans, and the luminescent bacteria Photobacterium leiognathi Sh1.

Methods: Isolates of pathogenic bacteria obtained from bronchoalveolar and peritoneal lavage samples from Wistar rats with experimental pneumonia and peritonitis were tested for their susceptibility to silver nanoparticles in solution with an alginate stabilizer. The antifungal activity of silver nanoparticles in sodium alginate was studied for $C$. albicans (strain CCM885) using the Sabouraud agar method. The biocidal impact of silver nanoparticles in solution with a sodium alginate matrix on the luminescent bacteria P. leiognathi Sh1 was investigated using a BLM 8801 luminometer.

Results: It was observed that a $0.02-0.05 \%$ nanosilver solution with an alginate stabilizer limits the growth and development of pathogenic bacteria within the first 24 hours of exposure. If the concentration of nanosilver solution is $0.0005-0.05 \%$, it inhibits the viability of the fungus $C$. albicans. A nanosilver solution at a concentration of $0.05-0.2 \mu \mathrm{g} / \mathrm{mL}$ represses bioluminescence in the bacteria $P$. leiognathi Sh1. From these results, it appears that the biocidal effect of nanosilver is related either to the presence of ions that are formed during dissolution, or to the availability of nanoparticles that interrupt the membrane permeability of bacterial cells.

Conclusion: Silver nanoparticles stabilized in a solution of sodium alginate possess significant in vitro antimicrobial activity, which is manifested by inhibition of the bioluminescence of $P$. leiognathi Sh1, and inhibition of the growth and development of the pathogenic bacteria S. aureus, E. faecalis, E. coli, P. vulgaris, E. cloacae, the antibiotic-resistant strain of $P$. aeruginosa, and the fungus $C$. albicans.

Keywords: Silver nanoparticles; Sodium alginate; Yeast-like fungi; Pathogenic bacteria; Luminescent bacteria

\section{Anatoliy Kubyshkin ${ }^{1}$, Denis Chegodar', Andrew Katsev ${ }^{1}$, Armen Petrosyan², Yuri Krivorutchenko ${ }^{3}$ and Olga Postnikova ${ }^{3}$}

1 Department of Clinical and General Pathophysiology, Medical Academy named after S.I. Georgievsky of V.I. Vernadsky CFU, Simferopol, Russia

2 Department of Biochemistry and Molecular Biology, College of Medicine, University of Nebraska Medical Center, Omaha, NE, USA

3 Department of Microbiology, Virology and Immunology, Medical Academy named after S.I. Georgievsky of V.I. Vernadsky CFU, Russia

Corresponding author:

Dr. Anatoliy Kubyshkin

戸 anatoly2802@gmail.com

Department of Clinical and General Pathophysiology, Medical Academy named after S.I. Georgievsky of V.I. Vernadsky CFU, Simferopol, Russia.

Tel: 3652554940

Citation: Kubyshkin A, Chegodar D, Katsev A, et al. Antimicrobial Effects of Silver Nanoparticles Stabilized in Solution by Sodium Alginate.

Biochem Mol Biol J. 2016, 2:2.

Received: May 23, 2016; Accepted: July 15, 2016; Published: July 20, 2016

\section{Introduction}

Investigation of the biological properties of the metal nanoparticles associated with significant recent progress in nanomedicine and nanopharmacology is one of the priorities of current research [1]. Nanomedicine studies the possibility of using nanotechnologies in the practice of medicine to, diagnose, treat, and prevent various diseases [2]. Investigation of the mechanisms of action of drugs based on silver nanoparticles is of particular interest [3].
It should be noted that silver-based drugs have been used as antiseptic and anti-inflammatory agents for quite a long time [4]. The advent of nanosized silver led to the development of drugs with stronger bactericidal, antiviral, antifungal, and antiseptic effects, with the ability to act as high-efficiency disinfectants for a broad range of pathogenic microorganisms [5]. The areas of contact between nanosilver and bacteria/viruses are greatly 
increased due to the highly specific surface area of nanoparticles, which significantly enhances the bactericidal properties of nanosilver. Hence, the use of silver nanoparticles in a solution allows one to reduce the metal concentration by a factor of several hundreds, while the bactericidal properties remain unchanged [6].

However, the possibility of putting silver nanoparticles to practical use faces a number of challenges, the most significant of which is the production of nano-sized particles within a standard size range along with the creation of stable colloidal systems that prevent agglomeration of the nanoparticles. The search for the optimal nanoparticle stabilizer is the most difficult task, but there are many ways to approach solving it [7].

One of the most promising stabilizers for potential use with silver nanoparticles is that derived from natural polymers, such as the structural polysaccharides of plants, which also have a wide spectrum of biological activity [8]. Studies have shown that the polysaccharide alginate derived from seaweed is a highly effective stabilizer, providing a high stability aggregation for silver nanoparticles [9].

The potential for using silver nanoparticles requires further thorough research because their toxicity has not yet been clarified. The development of nanotoxicology for these nanoparticles requires rapid new methods for quantitative control that allow evaluation of the biological effect of different nanoforms [10]. The luminescent bacteria toxicity assay, which consists of studying the inhibition of bioluminescence in photobacteria, was proposed as a method to evaluate the toxicity of nanoparticles. The reduced bacterial luminescence is currently attributed to manifestations of toxicity, ecotoxicity, and biocidal and antibiotic properties, etc. A period of ten to fifteen minutes is long enough to quantitatively assess the acute effect on the samples, which makes this method promising for rapid use (in particular, under field conditions) $[10,11]$.

The aim of this study was to investigate the effect of a nanosilver solution in a matrix of sodium alginate on the growth and development of pathogenic bacteria (S. aureus, E. faecalis, $E$. coli, $P$. vulgaris, E. cloacae, $P$. aeruginosa), the yeast-like fungus C. albicans, and on the reduction of bioluminescence in the luminescent bacteria $P$. leiognathi Sh1, so as to determine the possibility of using luminescent bacteria to assess the toxicity of nanoparticles.

\section{Methods}

\section{Silver nanoparticles solution with alginate stabilizer}

A nanobiocomposition consisting of $0.1 \%$ (weight/volume) silver nanoparticles $10-20 \mathrm{~nm}$ in size suspended in a sodium alginate matrix $(0.6 \%)$ and in aqueous medium (99.3\%) was used. The composition was developed at the Taurida National University (Simferopol) and the Institute of Biology of the Southern Seas (Sevastopol) [12]. Investigation of this nanosilver solution stabilized by sodium alginate included studying its antibacterial, antifungal, and biocidal effects using a luminescent bacteria assay.

\section{S. aureus, E. faecalis, E. coli, P. vulgaris, E. cloacae, $P$. aeruginosa isolates}

The antibacterial effect of nanosilver solution with an alginate stabilizer was investigated on bacterial isolates of $S$. aureus, $E$. faecalis, E. coli, P. vulgaris, and E. cloacae obtained by inoculating onto agar the bronchoalveolar and peritoneal lavage samples obtained from laboratory rats experimentally simulated with pneumonia and fecal peritonitis. The experiment was performed on 4 male white Wistar rats with body weights of $180-210 \mathrm{~g}$. The study was approved by the University Bioethics Committee and complied with the principles of the Guide for the Care and Use of Laboratory Animals (US NIH, no. 85-23, the 1985 edition).

The animals were divided into two experimental groups. In group 1 animals $(n=2)$, peritonitis was simulated by introduction of a $10 \%$ filtered fecal suspension at a dose of $0.5 \mathrm{~mL} / 100 \mathrm{~g}$ body weight. In group 2 animals $(n=2)$, obstructive pneumonia was simulated by insertion of a $2 \mathrm{~cm}$ long fishing line into the trachea and its subsequent fixation to the muscle.

The animals were anesthetized with ether within $24 \mathrm{~h}$ of developing peritonitis or pulmonary inflammation, then euthanized by decapitation followed by sample collection. Peritoneal lavage samples were obtained by washing the abdominal cavity 5 times with $10 \mathrm{~mL}$ isotonic $\mathrm{NaCl}$ solution (IS) for $1 \mathrm{~min}$ followed by aspiration using a syringe. Bronchoalveolar lavage samples were obtained after the pulmonary cardiac complex was isolated by washing the lungs with $10 \mathrm{~mL}$ of IS through the trachea.

The resulting bronchoalveolar and peritoneal lavage samples were inoculated onto beef extract agar and incubated at $37^{\circ} \mathrm{C}$ for $24 \mathrm{~h}$. S. aureus, E. faecalis and E. coli bacteria were isolated from the bronchoalveolar lavage samples; $P$. vulgaris and E. cloacae were isolated from the peritoneal lavage samples.

In addition, the effect of nanosilver was studied on a pathogenic antibiotic resistant isolate of $P$. aeruginosa derived from the sputum of a patient from the intensive care unit. An antibiogram obtained using the conventional disc method showed that this isolate was resistant to 10 of 11 studied antibacterial drugs analyzed.

\section{Estimation of antibacterial action by the serial dilution method}

The sensitivity of microorganisms to the nanosilver solution was determined using the dilution method. The initial $0.1 \%$ nanosilver solution was diluted with sterile $0.9 \% \mathrm{NaCl}$ solution to concentrations of $0.05 \%, 0.02 \%, 0.01 \%, 0.005 \%, 0.0025 \%$, and $0.00125 \%$. The resulting different concentrations of nanosilver solutions were added to beef extract broth. The bacterial suspension, which had a density corresponding to the McFarland Turbidity Standard No. 0.5 (with a microorganism concentration of $1.5 \times 10^{8}$ ), was added dropwise to each vial of the different concentrations of nanosilver solution, except for the control vial. The vials were incubated at $37^{\circ} \mathrm{C}$; the results were assessed visually after $24 \mathrm{~h}$ and $48 \mathrm{~h}$ according to either the presence or absence of turbidity in the experimental vials. Confirmation of the results was performed by subsequent inoculation of the 
experimental samples onto blood agar. The sensitivity of bacteria to a $1 \%$ solution of sodium alginate was used as a control.

\section{Candida albicans isolate}

The effect of nanosilver solution on yeast-like fungi was determined by observing the degree of fungal growth inhibition after incubation of the sample under study in accordance with the European Standard for determining the rate of microbial inactivation by antiseptic agents (European Standard EN 1040, 1997). The antifungal activity of silver nanoparticles in sodium alginate (experimental samples) and pure sodium alginate (control samples) was studied for the yeast-like fungus $C$. albicans, strain CCM885 (type strain). Yeast-like fungus $C$. albicans had been examined in the study because this microorganism is the most common human fungal pathogen.

\section{Estimation method of antifungal action}

Nanosilver was diluted in sterile distilled water to a concentration of $0.05 \%$. The solution was kept at $37^{\circ} \mathrm{C}$ for $10 \mathrm{~min}$ and then diluted 10 - or 100 -fold with distilled water supplemented with the fungus culture to be tested to a final concentration of $5 \times 10^{6}$ $\mathrm{CFU} / \mathrm{mL}$. The final nanosilver concentrations were $0.005 \%$ and $0.0005 \%$. Fungus concentrations were confirmed by control inoculation onto Sabouraud agar. Diluted nanosilver solutions with fungus added were incubated at $37^{\circ} \mathrm{C}$ for $1 \mathrm{~h}$ or $24 \mathrm{~h}$ followed by subculturing and counting live microorganisms. The resulting mixtures $(10 \mathrm{~mL})$ were placed in flat-bottomed flasks and incubated on a rotary incubator at a mixing rate of $100 \mathrm{rpm}$ at $37^{\circ} \mathrm{C}$ for $1 \mathrm{~h}$ or $24 \mathrm{~h}$. The material was then inoculated onto Sabouraud agar and cultured at $28^{\circ} \mathrm{C}$ for $48 \mathrm{~h}$. The number of resulting fungal colonies was counted. Aqueous alginate solution (1\%) mixed with fungus to a final concentration of $5 \times 10^{6} \mathrm{CFU} / \mathrm{mL}$ was analyzed as the control sample.

\section{Estimation method of biocidal activity}

The biocidal activity of nanosilver solution was studied using a luminous marine bacteria isolated from the Sea of Azov identified as Photobacterim leiognathi Sh1. To assess the acute effect of the nanosilver solution, $0.9 \mathrm{~mL}$ of either $2.5 \% \mathrm{NaCl}$ or $30 \%$ sucrose, 1-50 $\mu \mathrm{L}$ of the test sample, and $50-100 \mu \mathrm{L}$ of the diluted $1: 100$ suspension of luminous bacteria were mixed in luminometer cuvettes. The changes in bioluminescence intensity were recorded for $30 \mathrm{~min}$, after which the data were processed [11,13].

The chronic effect was assessed by adding $25 \mu \mathrm{L}$ of the nutrient medium for luminous bacteria to the samples prepared as described above. The samples were incubated for $15-18 \mathrm{~h}$ and the intensity of bacterial luminescence was determined. The results are represented as bioluminescence intensity calculated using the formula $I=\left(I_{i} / I_{0}\right) 100 \%$, where $I_{i}$ and $I_{0}$ are bioluminescence intensities in the sample and control, respectively. Samples consisting of $0.9 \% \mathrm{NaCl}, 50-100 \mu \mathrm{L}$ of bacterial suspension, and $25 \mu \mathrm{L}$ of nutrient medium (if the chronic effect was measured) were used as controls [11,13].

To study the direct effect of nanosilver solution on the luminous bacteria $P$. leiognathi Sh1, the following experiment was performed. The bacterial suspension was grown in liquid medium for $18 \mathrm{~h}$ at $25^{\circ} \mathrm{C}$, then applied evenly on the surface of the agar nutrient medium prepared by the same conditions, followed by incubation at $25^{\circ} \mathrm{C}$ for another $18 \mathrm{~h}$. Then, $10 \mu \mathrm{L}$ nanosilver solutions containing 1,2 , or $5 \mu \mathrm{g}$ of nanoparticles were applied to the surface of the bacterial layer and incubated for $30 \mathrm{~min}$ at $25^{\circ} \mathrm{C}$. Pictures of the glowing bacterial field were obtained in a dark room using a Canon EOS 600D camera in automatic mode at maximal resolution $(5184 \times 3456$ pixels). Bioluminescence intensity was measured using the statistical tools of IMARIS versions 7.2.2-7.6.0 (Bitplane Scientific). Conductivity was measured using a Dist 3 conductivity meter (Hanna Instrument, Germany). Bioluminescence intensity was recorded in relative units (mV) using BLM 8801, a photomultiplier-based luminometer (Nauka, Russia).

\section{Statistical analysis}

All of the experiments were carried out three times each, independently. The data obtained were expressed in terms of 'mean \pm standard deviation' values. Depending upon the nature of the data, Student's T test with either two independent samples or paired samples and Mann-Whitney U-test was used. A probability value $<0.05$ was considered statistically significant. Calculations were made using the software package Statistica 6.0 by StatSoft (USA).

\section{Results and Discussion}

\section{Antibacterial effects}

As these studies have shown, experimental isolates of the bacteria S. aureus, E. faecalis, E. coli, P. vulgaris, and E. cloacae, as well as the antibiotic-resistant strain of $P$. aeruginosa (Pseudomonas aeruginosa), were sensitive to a solution of silver nanoparticles suspended in sodium alginate, and the sensitivity of microorganisms depended on the concentration of the solution. Thus, when prototypes were assessed visually $24 \mathrm{~h}$ after initiation of the study, no haze was observed in test tubes with a solution of silver nanoparticles + alginate stabilizer at concentrations of $0.05 \%$ or $0.02 \%$, indicating total inhibition of the growth and reproduction of bacteria during the first day. Visual examination of the test tubes with a solution of silver nanoparticles + alginate stabilizer at concentrations of $0.01 \%, 0.005 \%, 0.0025 \%$, or $0.00125 \%$ detected a slight opacification, which indicated only the partial inhibition of growth of pathogenic bacteria during this time period (Table 1).

Control samples of the bacterial isolates S. aureus, E. faecalis, E. coli, P. vulgaris, E. cloacae, and $P$. aeruginosa exhibited visible bacterial growth within $24 \mathrm{~h}$ of the beginning of the study, as characterized by clouding of the control tubes. This visual bacterial growth also seems to indicate that the sodium alginate stabilizer had no inhibitory effect on the bacteria.

Visual assessment of prototypes and control after $48 \mathrm{~h}$ of incubation showed that a nanosilver solution at a concentration of $0.05 \%$ or $0.02 \%$ completely inhibited the growth and development of experimental isolates of the bacteria $S$. aureus, $E$. faecalis, E. coli, P. vulgaris, E. cloacae, and P. aeruginosa. However, in tubes with highly diluted solutions of silver nanoparticles, at concentrations of $0.01 \%, 0.005 \%, 0.0025 \%$, or $0.00125 \%$, as well 
Table 1 Effect of silver nanoparticle solution with the sodium alginate stabilizer on bacteria after 24 h. "-": no culture growth; "+": culture growth detected.

\begin{tabular}{|c|c|c|c|c|c|c|c|}
\hline $\begin{array}{l}\text { Concentration of } \\
\text { silver panoparticles } \\
\text { soldtion } \\
\text { Bacteria isolates }\end{array}$ & $\begin{array}{l}\text { ํํ } \\
\text { ํㅜ }\end{array}$ & $\begin{array}{l}\stackrel{0}{O} \\
\text { Oे }\end{array}$ & $\begin{array}{l}\stackrel{\circ}{\circ} \\
\stackrel{\circ}{\circ} \\
\circ\end{array}$ & 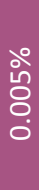 & $\begin{array}{l}\text { 今े } \\
\text { ஸे } \\
\text { ○े }\end{array}$ & $\begin{array}{l}\stackrel{\circ}{\mathrm{i}} \\
\text { 공 } \\
\text { ○. }\end{array}$ & 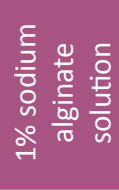 \\
\hline S. aureus & - & - & + & + & + & + & + \\
\hline E. faecalis & - & - & + & + & + & + & + \\
\hline E. coli & - & - & + & + & + & + & + \\
\hline P. vulgaris & - & - & + & + & + & + & + \\
\hline E. cloacae & - & - & + & + & + & + & + \\
\hline$P$. aeruginosa & - & - & + & + & + & + & + \\
\hline
\end{tabular}

as in the control test tube with a $1 \%$ solution of sodium alginate, within $48 \mathrm{~h}$ of the beginning of the experiment, ongoing growth and development of microorganisms was observed.

As a control, we conducted a separate sowing of medium, a solution of silver nanoparticles with sodium alginate, and culture microorganisms. After 24 and $48 \mathrm{~h}$ of incubation in the medium and in the solution of silver nanoparticles, visual growth of bacteria was detected. Sowing of isolates of the bacteria S. aureus, E. faecalis, E. coli, P. vulgaris, E. cloacae, and P. aeruginosa on the medium without treatment with a solution of silver nanoparticles resulted in a stable growth of microorganisms.

\section{Antifungal effects}

The data obtained by studying the effect of nanosilver solution and alginate on a yeast-like fungus demonstrated that nanosilver at concentrations of $0.0005-0.005 \%$ in aqueous media was able to completely inhibit the viability of $C$. albicans over $24 \mathrm{~h}$. For the exposure time of $1 \mathrm{~h}$, a nanosilver solution at a concentration of $0.0005 \%$ had no effect on the viability of fungi, while that at a concentration of $0.005 \%$ reduced the count of viable microbial cells fivefold. Sodium alginate (1\%) alone had no significant effect on viability of the yeast-like fungus (Table 2 ).

\section{Biocidal action}

When studying the effect of silver nanoparticles in a sodium alginate gel matrix on the bioluminescence of the bacteria $P$. leiognathi Sh1, compared to the effects of silver nitrate or silver alginate, the experiments demonstrated that, while nanosilver and silver nitrate inhibit bioluminescence, silver alginate had virtually no effect on it (Figure 1).

The absence of any effect of the silver-alginate complex shows that the bond between the polysaccharide and the metal is strong (which coincides with the data available in the literature) and that those alginates are capable of tightly binding heavy metal ions [14].

The kinetic parameters for the effect of nanosilver were virtually identical to those for silver nitrate (Figure 2), although theoretically silver ions might be expected to cause a more rapid effect than that of nanoparticles. The effective concentrations, which induce $50 \%$ bioluminescence inhibition ( $\mathrm{EC}_{50}$ ), in a $30-\mathrm{min}$ bioassay for nanosilver and silver nitrate were 0.3 and $0.4 \mu \mathrm{g} / \mathrm{mL}$, respectively.
Taking into account the fact that the bioassay based on luminescent bacteria according to the standard procedure is performed in $3 \%$ $\mathrm{NaCl}$, it can be hypothesized that silver nanoparticles coagulate under these conditions, while a colloidal $\mathrm{AgCl}$ solution is formed in the $\mathrm{AgNO}_{3}$ solution. Thus, silver in both samples is represented by colloidal particles of a larger size than was expected, which explains the reason for the identical inhibition kinetics associated with the rate of penetration through the bacterial cell membrane.

Additional studies of the direct effect of nanosilver solution on the luminous bacteria $P$. leiognathi Sh1 were performed using
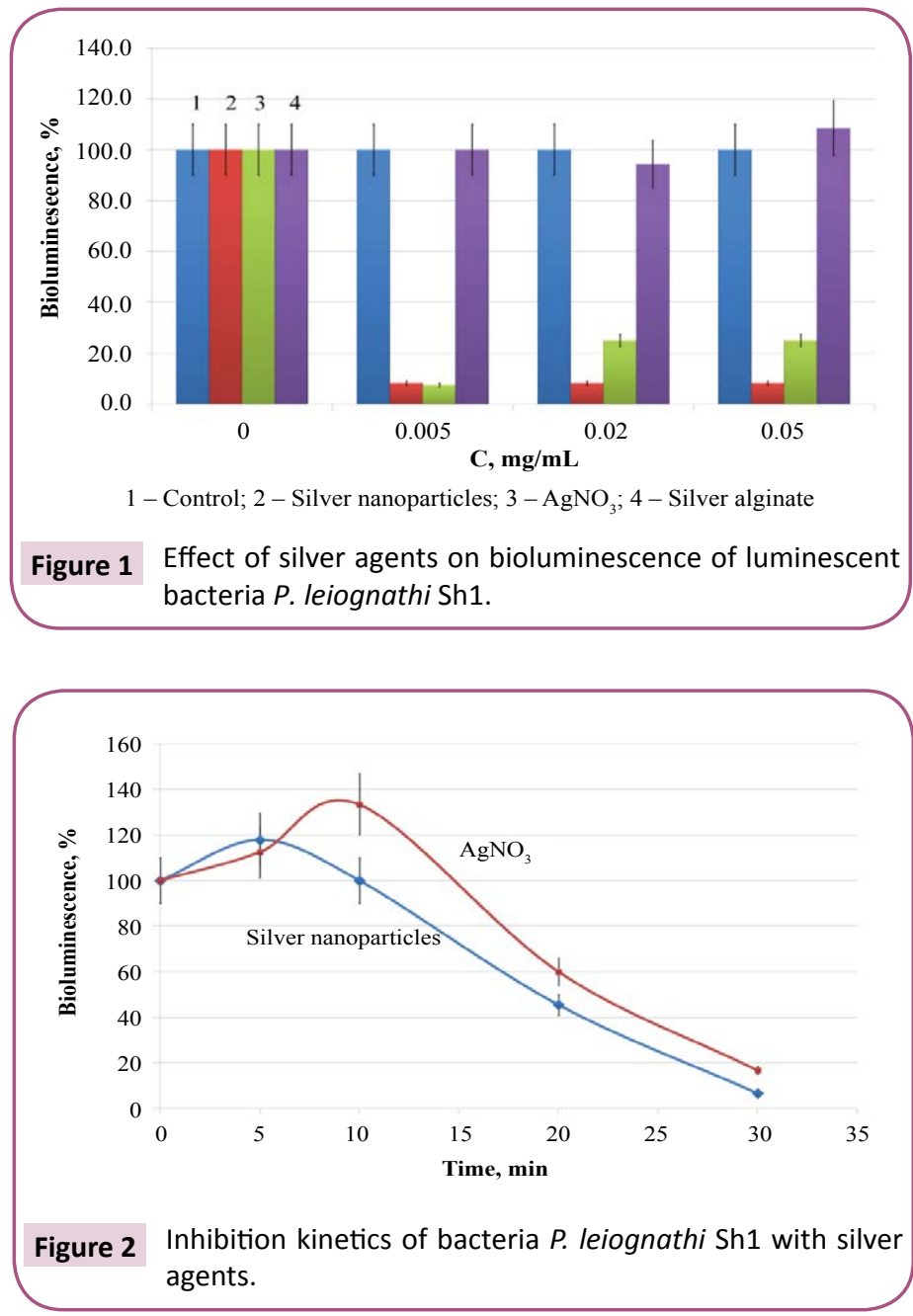

Table 2 Effect of silver nanoparticle solution supplemented with alginate on the yeast-like fungus Candida albicans CCM885. "-": no effect or culture growth; “*”: fungi growth detected.

\begin{tabular}{|c|c|c|c|c|c|c|}
\hline \multirow{3}{*}{$\begin{array}{l}\text { Variants } \\
\text { of the } \\
\text { experiment }\end{array}$} & \multirow{3}{*}{$\begin{array}{l}\text { Nanosilver } \\
\text { (\%) }\end{array}$} & \multirow{3}{*}{$\begin{array}{l}\text { Sodium } \\
\text { alginate } \\
\text { (\%) }\end{array}$} & \multicolumn{4}{|c|}{ Fungal concentration after } \\
\hline & & & \multicolumn{2}{|c|}{$\begin{array}{l}\text { CFU/mL after } \\
\text { incubation for }\end{array}$} & \multicolumn{2}{|c|}{$\begin{array}{l}\text { Multiplicity of } \\
\text { reduction }\end{array}$} \\
\hline & & & $1 \mathrm{~h}$ & $24 \mathrm{~h}$ & $1 \mathrm{~h}$ & $24 \mathrm{~h}$ \\
\hline Experiment & 0.005 & 0.03 & $10^{5}$ & 0 & 5 & 250000 \\
\hline Experiment & 0.0005 & 0.003 & $5 \times 10^{5}$ & 0 & -- & 250000 \\
\hline $\begin{array}{l}\text { Control of } \\
\text { the culture }\end{array}$ & 0 & 0 & $5 \times 10^{5}$ & $2.5 \times 10^{5}$ & -- & -- \\
\hline $\begin{array}{l}\text { Control of } \\
\text { alginate }\end{array}$ & -- & 1 & $10^{6}$ & $2.5 \times 10^{5}$ & $2^{*}$ & -- \\
\hline
\end{tabular}


bacteria on a solid medium in Petri dishes. Equal volumes of the samples were placed directly on the surface of a glowing bacterial field and the resultant changes in bioluminescence were recorded photographically (Figure 3).

In samples with 1 and $2 \mu \mathrm{g}$ of nanoparticles (Figures $3 \mathbf{b}, \mathbf{3 c}$, and 3e), it was observed that the relative intensity of bioluminescence was significantly lower than that in controls (Figure 3a): 126 (b), 110 (e), and 24 (c) vs. 180 (a), respectively. Also, in samples with 5 $\mu \mathrm{g}$ of nanoparticles (Figure $3 \mathbf{d}$ ), we found a robust decrease, with a bioluminescence intensity value of $\sim 9$.

It was also revealed that any changes in the dimensions of the sample dark zones due to diffusion were not observed during the duration of the experiment. These changes prove that the action of the nanosilver particles was in the form of big colloidal particles, evidently resulting from their reaction with $\mathrm{NaCl}$, which was present in the bacterial nutrition medium.

To eliminate the processes causing particle coarsening, and to compare the effect of silver nanoparticles with that of silver ions, further experiments were conducted in a $30 \%$ sucrose solution, which is isotonic to $2.5 \% \mathrm{NaCl}$. Bacterial luminescence was stable under these conditions, making it possible to perform a comparative bioassay. Lower concentrations of silver agents had an effect when the medium lacking sodium chloride was used. When the samples were exposed to silver agents at a concentration of $0.2 \mu \mathrm{g} / \mathrm{L}$, bioluminescence was reduced to zero. Silver alginate both in sucrose and in sodium chloride had no effect on bacterial luminescence. Determination of the $\mathrm{EC}_{50}$ showed that $50 \%$ inhibition in the medium lacking sodium chloride takes place at a nanosilver concentration of $0.085 \mu \mathrm{g} / \mathrm{mL}$, and at a silver nitrate concentration of $0.12 \mu \mathrm{g} / \mathrm{mL}$ (exposure time: $30 \mathrm{~min}$ ).

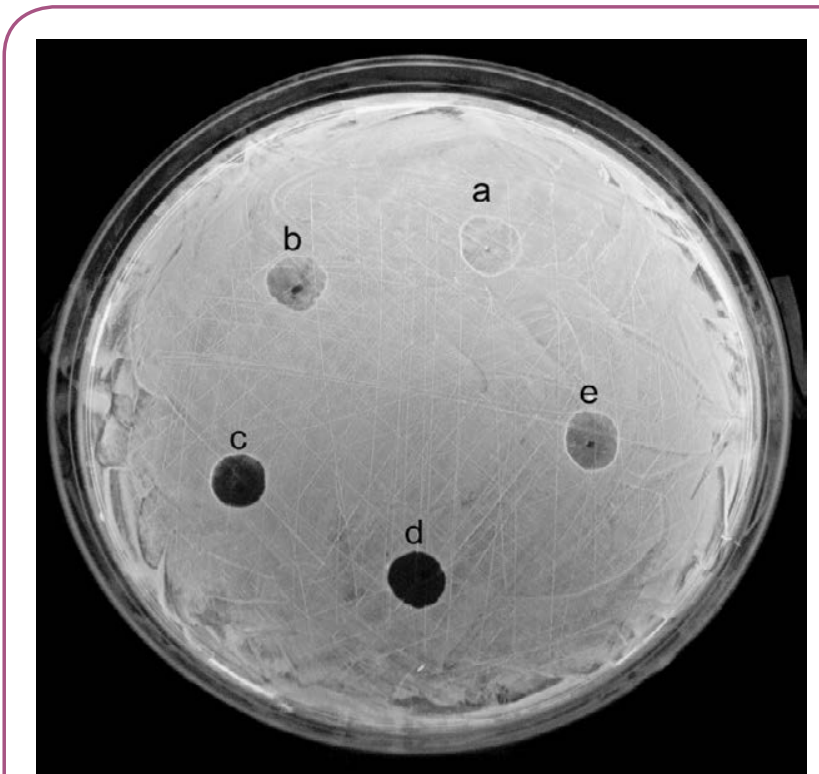

Figure 3 The direct effect of nanosilver solution on luminous bacteria $P$. leiognathi. The amounts of nanosilver were: $1 \mu \mathrm{g}$ (b and e), $2 \mu \mathrm{g}$ (c), and $5 \mu \mathrm{g}(\mathrm{d})$. The empty sample with $3 \% \mathrm{NaCl}$ served as a control (a). Bioluminescence intensity was measured using the statistical tools of IMARIS versions 7.2.2-7.6.0 (Bitplane Scientific).
The described effects of silver nanoparticles provide an opportunity to justify their current use in medical practice for a number of pathological conditions as an alternative to standard antibacterial and antifungal agents. Many of these agents have significant drawbacks, owing both to their inefficient action against antibiotic resistant microorganisms, and to the abnormal reactions and toxicities that they cause in patients. This has led to an intensive search for new substances with antimicrobial properties that has been carried out in many different directions, including experiments with substrates of natural origin, such as saponin tauroside Sx1, derived from Crimean ivy (Hedera taurica carr.), which suppresses the growth of Candida fungi, and experiments with other natural and synthetic compounds [15].

\section{Conclusion}

Analysis of the results of our research into the use of a solution of silver nanoparticles with sodium alginate for this purpose leads to the following main conclusions:

1. Silver nanoparticles in solution in the matrix of an alginate stabilizer at concentrations of $0.02-0.05 \%$ completely inhibit in vitro growth and development of the pathogenic bacteria $S$. aureus, E. faecalis, E. coli, P. vulgaris, and $E$. cloacae.

2. Silver nanoparticles in solution in the matrix of an alginate stabilizer at concentrations of $0.02-0.05 \%$ inhibit the growth of the antibiotic-resistant strain of $P$. aeruginosa (which is resistant to 10 antibacterial drugs), thus demonstrating that solutions of silver nanoparticles stabilized in the matrix of natural polysaccharides such as sodium alginate can be used for the treatment of antibiotic-resistant strains.

3. The aqueous nanosilver solution supplemented with sodium alginate at nanosilver concentrations of 0.0005 $0.005 \%$ completely inhibits the viability of $C$. albicans within 24 h. Nanosilver at a concentration of $0.005 \%$ reduces the number of viable fungal cells fivefold within $1 \mathrm{~h}$, but has no effect on their viability when used at a concentration of $0.0005 \%$.

4. Nanosilver and silver nitrate were shown to have an identical effect on the bioluminescence of luminescent bacteria, as they inhibit it with effective constants $\mathrm{EC}_{50}$ $=0.3-0.4 \mu \mathrm{g} / \mathrm{mL}$ in the medium containing $3 \% \mathrm{NaCl}$ and $\mathrm{EC}_{50}=0.12 \mu \mathrm{g} / \mathrm{mL}$ in the salt-free medium containing $30 \%$ sucrose. Silver alginate had no biocidal effect.

During experiments it was established that the biocidal mechanism of a nanosilver solution can be associated both with the formation of silver ions during dissolution and with the damage caused to bacterial cell membranes by nanoparticles. These results demonstrate that toxicity depends strictly on particle size, and that the biological effect decreases as the particles become larger. In addition, the effect of silver nanoparticles and silver ions is observed at similar concentrations, which argues in favor of identical mechanisms for the biocidal effect. To compare the ionic composition of the samples under study, we measured their conductivity in distilled water at a dilution rate of 100 . The results 
demonstrated that the $\mathrm{AgNO}_{3}$ solution had the lowest specific conductivity $(3 \mu \mathrm{S} / \mathrm{cm})$. Specific conductivities of nanosilver and silver alginate solutions at the same concentrations were $13 \mu \mathrm{S} /$ $\mathrm{cm}$ and $9 \mu \mathrm{S} / \mathrm{cm}$, respectively. Thus, the ionic mechanism may be one of the mechanisms responsible for nanosilver toxicity; the higher conductivity values could be caused by the presence of alginates in the samples.

It has been demonstrated in a number of studies that the effect of silver nanoparticles $\sim 10 \mathrm{~nm}$ in size is related both to the presence of ions formed during dissolution and to the presence of nanoparticles, which interrupt the integrity of the cell membrane as they penetrate through it, causing cell death and thus enhancing its sensitivity to the effect of toxic factors of different etiology [16]. The sensitivity of luminescent bacteria pretreated with low nanosilver concentrations to copper sulfate was studied to verify this hypothesis (Figure 4). The copper salt was selected because $\mathrm{Cu}^{2+}$ ions affect the enzymatic apparatus of bacteria as they penetrate into the cell through its membrane [17].

Luminescent bacteria were treated with threshold concentrations of nanoparticles $(0.05 \mu \mathrm{g} / \mathrm{mL})$; at these concentrations, no significant changes in bioluminescence levels occurred within 10$30 \mathrm{~min}$. The results demonstrated that the bacteria treated with nanoparticles for $10 \mathrm{~min}$ are more susceptible to the influence of copper ions than the untreated ones (Figure 4). The effective concentrations $\left(\mathrm{EC}_{50}\right)$ of copper sulfate for the untreated and treated luminescent bacteria were $2 \mu \mathrm{g} / \mathrm{mL}$ and $0.2 \mu \mathrm{g} / \mathrm{mL}$, respectively.

Thus, the results verify the existing hypothesis concerning the combined mechanism of action of nanoparticles, which is associated both with the particles and with their ions, which form when nanoparticles dissolve [16]. Treatment with nanoparticles interrupts the integrity of the bacterial call wall, which is the mechanism of toxic action of nanoparticles and facilitates penetration of copper ions into the cell. The mechanism involving the formation of toxic reactive oxygen species (ROS) cannot be ruled out: the formation of ROS can be induced both by nanoparticles and by copper ions [17]. The treated bacteria could have an increased intracellular concentration of ROS, which in turn caused a higher toxicity as the result of copper ions.

Furthermore, there are data indicating that silver ions, after they are adsorbed onto the surface of a microbial cell and penetrate into it, are capable of inhibiting the respiratory chain enzymes. This results in disintegration of the oxidation and phosphorylation processes in microbial cells, which may cause cell death $[5,18]$.

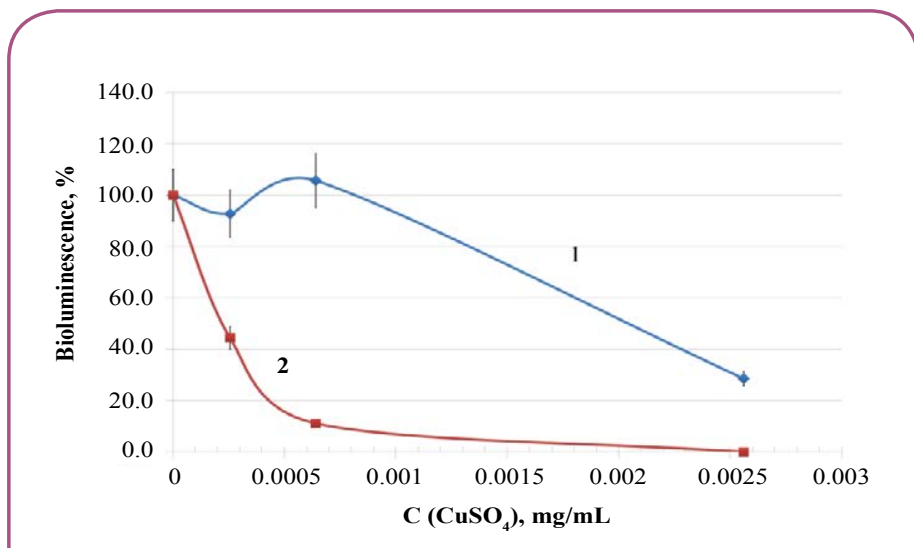

Figure 4 Effect of copper sulfate on luminescent bacteria $P$. leiognathi Sh1: 1- intact; 2- treated with $0.05 \mu \mathrm{g} / \mathrm{mL}$ silver nanoparticles for $10 \mathrm{~min}$.

Silver is believed to have virtually no effect on mammalian cells due to the fundamentally different structure of their cell membranes [19-21].

It should be mentioned that the use of a nanosilver solution to treat bacterial inflammation has been demonstrated using an acute peritonitis model in rats [22]. The study showed that intraperitoneal introduction of nanosilver reduced the development of inflammation in the abdominal cavity, which manifested as reduced activity of nonspecific proteinases, stabilization of the level of their inhibitors, and reduction of systemic signs of peritonitis.

In addition, research has shown that the use of seaweed polysaccharide sodium alginate as a stabilizer for nanoparticles provides a highly stable solution of silver nanoparticles that has significant antibacterial and antifungal activity, as well as a biocidal effect with respect to luminescent bacteria, which enables the development of new methods for the assessment of the toxicity of nanoparticles.

\section{Conflict of Interest}

All contributing authors declare no conflicts of interest.

\section{Acknowledgment}

The authors would like to thank the Department of Physical and Analytical Chemistry of V.I. Vernadsky Crimean Federal University and especially professor assistant I.N. Yurkova for preparation of the silver nanoparticle solution. 


\section{References}

1. Chekman IS (2012) Nanopharmacology: View of Problem. Herald of the NAS of Ukraine 7: 21-25.

2. Chekman IS (2009) Nanoparticles: Properties and prospects of application. Ukrainian Biochemical Journal 81: 22-129.

3. Egorova EM, Kubatiev AA, Shvets VI (2014) Biological effects of metal nanoparticles. Moscow.

4. Chekman IS, Movchan BA, Zagorodnyi MI, Gaponov YuV, Kurapov YuA et al. (2008) Nanosilver: technology of production, pharmacological properties, indication to the application. Journal Art of Treatment 51: 32-34.

5. Ribachuk AV, Chekman IS (2009) Antimicrobial properties of nanosilver. Ukrainian Scientific Medical Youth Journal 2: 32-36.

6. Gusev Al (2007) Nanomaterials, Nanostructures, Nanotechnologies. Moscow.

7. Chekman IS (2009) Nanoscience: prospects of scientific investigation. Science and Innovation 5: 89-93.

8. Pomogailo AD, Rozenberg AS, Uflyand UE (2000) Nanoscale metal particles in polymers.

9. Yurkova IN, Panova EP, Ryabushko VI, Panov DA (2009) Alginates of marine algae - perspective polymeric matrix for nanobiocomposites of silver. Thesis of the international conference. Applied Physical Chemistry and Nanochemistry 6: 158-159.

10. Lopes I, Ribeiro R, Antunes FE, Rocha-Santos TAP, Rasteiro MG, et al. (2012) Toxicity and genotoxicity of organic and inorganic nanoparticles to the bacteria Vibrio fischeri and Salmonella typhimurium. Ecotoxicology 21: 637-648.

11. Katsev AM, Goister OS, Starodub NF (2003) Effect of mycotoxin T-2 on bioluminescence intensity of bacteria. Ukr Biokhim Zh 75: 99-103.

12. Yurkova IM, Estrella-Llopis VR, Ryabushko VI, Ryabushko LI (2005) A method of producing a water-soluble anti-bacterial composition containing silver nanoparticles.
13. Kur'ianov VO, Chupakhina TA, Shapovalova AA, Katsev AM, Chirva VIA (2011) Glycosides of hydroxylamine derivatives. I. phase transfer synthesis and study of isatine-3-oximes glucosaminides influence on bacterial luminescence. Bioorg Khim 37: 259-268.

14. Davis TA, Volesky B, Mucci A (2003) A review of the biochemistry of heavy metal biosorption by brown algae. Water Res 37: 4311-4330.

15. Melnichenko EG, Kirsanova MA, Grishkovets VI, Tyshkevich LV, Krivorutchenko YuL (2003) The study of antimicrobial activity of saponins from Crimean ivy (Hedera taurica carr.). Microbiological Journal 65: 8-12.

16. Beer C, Foldbjerg R, Hayashi Y (2012) Toxicity of silver nanoparticles - nanoparticle or silver ion? Toxicol Lett 208: 286-292.

17. Wang W, Lampi MA, Huang XD (2009) Assessment of mixture toxicity of copper, cadmium, and phenanthrenequinone to the marine bacterium Vibrio fischeri. Environ Toxicol 24: 166-177.

18. Melaiye A, Sun Z, Hindi K (2005) Silver(I)-imidazole cyclophane gemdiol complexes encapsulated by electrospun tecophilic nanofibers: formation of nanosilver particles and antimicrobial activity. J Am Chem Soc 127: 2285-2291.

19. Braydish-Stolle L, Hussain S, Schlager J (2005) In vitro cytotoxicity of nanoparticles in mammalian germline stem cells. Toxicological Sciences 88: 412-419.

20. Soni I, Salopek-Bondi B (2004) Silver nanoparticles as antimicrobial agent: a case study on E. coli as a model for Gram-negative bacteria. J Colloid Interface Sci 27: 70-82.

21. Chekman IS, Priskoka AO, Babii VF, Antonenko OV, Zagorodnii MI (2010) Medical application of silver nanoparticles: toxicological aspect. Modern Problems of Toxicology 4: 10-13.

22. Babanin AA, Kubyshkin AV, Ermola YuA, Chegodar DV, Yurkova IN, et al. (2014) Changes of nonspecific proteinases and free-radical oxidation processes in treatment of experimental peritonitis with the nanobiosilver solution. The New Armenian Medical Journal 8 : 46-51. 